\title{
Regulation of the Development of Mesencephalic Dopaminergic Systems by the Selective Expression of Glial Cell Line-Derived Neurotrophic Factor in Their Targets
}

\author{
Nikolai Kholodilov, ${ }^{1}$ Olga Yarygina, ${ }^{1}$ Tinmarla Frances 0o, ${ }^{1}$ Hui Zhang, ${ }^{1}$ David Sulzer, ${ }^{1,2}$ William Dauer, ${ }^{1,3}$ and \\ Robert E. Burke ${ }^{1,4}$ \\ Departments of ${ }^{1}$ Neurology, ${ }^{2}$ Psychiatry, ${ }^{3}$ Pharmacology, and ${ }^{4}$ Pathology, College of Physicians and Surgeons, Columbia University, New York, New York \\ 10032
}

\begin{abstract}
Glial cell line-derived neurotrophic factor (GDNF) has been shown to protect and restore dopamine (DA) neurons in injury models and is being evaluated for the treatment of Parkinson's disease. Nevertheless, little is known of its physiological role. We have shown that GDNF suppresses apoptosis in DA neurons of the substantia nigra (SN) postnatally both in vitro and during their first phase of natural cell death in vivo. Furthermore, intrastriatal injection of neutralizing antibodies augments cell death, suggesting that endogenous GDNF plays a role as a target-derived factor. Such a role would predict that overexpression of GDNF in striatum would increase the surviving number of SN DA neurons. To test this hypothesis, we used the tetracycline-dependent transcription activator (tTA)/tTA-responsive promoter system to create mice that overexpress GDNF selectively in the striatum, cortex, and hippocampus. These mice demonstrate an increased number of SN DA neurons after the first phase of natural cell death. However, this increase does not persist into adulthood. As adults, these mice also do not have increased dopaminergic innervation of the striatum. They do, however, demonstrate increased numbers of ventral tegmental area (VTA) neurons and increased innervation of the cortex. This morphologic phenotype is associated with an increased locomotor response to amphetamine. We conclude that striatal GDNF is necessary and sufficient to regulate the number of SN DA neurons surviving the first phase of natural cell death, but it is not sufficient to increase their final adult number. GDNF in VTA targets, however, is sufficient to regulate the adult number of DA neurons.
\end{abstract}

Key words: apoptosis; programmed cell death; neurotrophic factors; Parkinson's disease; striatum; substantia nigra

\section{Introduction}

Glial cell line-derived neurotrophic factor (GDNF) was identified on the basis of its ability to support the development of embryonic dopamine (DA) neurons (Lin et al., 1993). It has been shown in numerous experiments to both protect and restore DA neurons of the substantia nigra ( $\mathrm{SN}$ ) in many different lesion models (Bowenkamp et al., 1995; Sauer et al., 1995; Tomac et al., 1995a; Gash et al., 1996; Choi-Lundberg et al., 1997; Kordower et al., 2000). Although initial attempts to use it therapeutically for Parkinson's disease by intraventricular injection were unsuccessful (Nutt et al., 2003), more recent efforts using direct intraputaminal infusion have been more promising (Gill et al., 2003). Despite the clear functional effects GDNF has on the neurobiology of DA neurons, there has been no information about its normal physiological role, if any, in their development or maintenance.

We and others have shown that DA neurons of the SN, like most neurons, undergo normal developmental cell death; the

Received 0ct. 3, 2003; revised Feb. 5, 2004; accepted Feb. 10, 2004.

This work was supported by National Institutes of Health Grants NS26836 and NS38370, The Parkinson's Disease Foundation, and the Lowenstein Foundation.

Correspondence should be addressed to Robert E. Burke, Department of Neurology, Room 308, Black Building, Columbia University, 650 West 168th Street, New York, NY 10032. E-mail: rb43@columbia.edu.

DOI:10.1523/JNEUROSCI.4506-03.2004

Copyright $\odot 2004$ Society for Neuroscience $\quad$ 0270-6474/04/243136-11\$15.00/0 event is primarily postnatal, and it is biphasic with peaks at postnatal days (PNDs) 2 and 14 (Janec and Burke, 1993; Mahalik et al., 1994; Oo and Burke, 1997; Jackson-Lewis et al., 2000; Groc et al., 2001a,b). As envisioned by classic neurotrophic theory (Clarke, 1985; Barde, 1989), this death event appears to be regulated by target interactions; it is augmented by disruption of such interactions by a target lesion (Macaya et al., 1994), DA terminal destruction (Marti et al., 1997), or axotomy (El-Khodor and Burke, 2002) during the first 2 weeks of life. We have evaluated the possibility that GDNF may serve as a physiological, limiting, target-derived factor for SN DA neurons. Its mRNA is present in striatum and expressed at high levels during early postnatal development (Schaar et al., 1993; Stromberg et al., 1993; Blum and Weickert, 1995; Choi-Lundberg and Bohn, 1995; Cho et al., 2003). We have shown that GDNF is able to support DA neurons by suppressing apoptosis in a postnatal primary culture model, established during the natural cell death period for these neurons (Burke et al., 1998). We have also shown in vivo that direct intrastriatal injection of GDNF suppresses the first phase of natural cell death on PND 2, whereas injection of neutralizing antibodies augments it (Oo et al., 2003), suggesting a regulatory role for endogenous GDNF.

The hypothesis that GDNF is a physiological, limiting, striatal target-derived neurotrophic factor for SN DA neurons predicts 


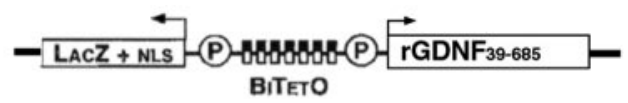

A

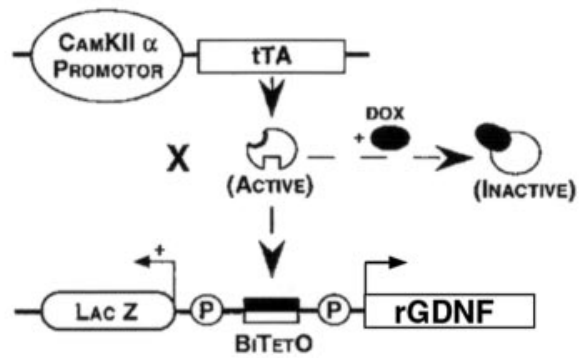

B

Figure 1. A double-transgenic approach to overexpression of GDNF in the principal target structures of the mesencephalic dopaminergic projection. $A$, The transgene incorporates a bidirectional promoter, driving expression of LacZ [with a nuclear localization signal (NLS)] in one direction and bp $39-685$ of rat GDNF in the other. $B$, When CaMKII $\alpha$-tTA monotransgenic mice are crossed with BiTet0-LacZ-rGDNF monotransgenics, the resulting double transgenics will express rGDNF (and LaCZ) only in those brain regions in which CaMKIl $\alpha$ is normally expressed: striatum, cortex, and hippocampus. Expression of GDNF can be suppressed by administration of doxycycline (DOX).

that increased expression of GDNF in targets throughout the natural cell death period should result in an increased number of surviving neurons. To test this hypothesis, we have generated mice that selectively express GDNF in striatum, hippocampus, and cortex. To accomplish this we generated a transgenic mouse containing a tetracycline-dependent transcription activator (tTA)-responsive bidirectional (Bi)TetO-LacZ-rat GDNF (rGDNF) transgene and crossed this mouse with the calcium/ calmodulin-dependent protein kinase II (CaMKII)-tTA transgenic mouse, as previously described (Mayford et al., 1996; Yamamoto et al., 2000). For this analysis, regionally specific expression in target regions is important not only for a direct test of the hypothesis but also to avoid a confounding effect of direct expression of GDNF within dopaminergic neurons, which, for reasons that are unknown, results in a decreased number of these neurons (Chun et al., 2002). We find, as predicted, that GDNF overexpression in the targets of mesencephalic DA neurons results in an increased number of SN DA neurons surviving the first phase of natural cell death. However, it does not increase the number surviving into adulthood. Thus target-derived GDNF alone is sufficient to forestall natural cell death in DA neurons only during the first phase early in their postnatal development.

\section{Materials and Methods}

Transgenic mice. The coding sequence for the rGDNF was obtained by performing reverse transcription-PCR on RNA derived from postnatal rat brain using primers to encompass bp 39-685 (GenBank accession number L15305). This fragment was inserted into multiple cloning site 2 in the appropriate orientation downstream to minimal promoter Pmin-1 in the bidirectional plasmid pBI-3 (Baron et al., 1995) (Fig. 1 A), kindly provided by Dr. René Hen (Columbia University, New York, NY). A $7.1 \mathrm{~kb}$ AseI fragment of this construct was microinjected by standard techniques into single-cell CBA $\times$ C57BL/ 6 embryos. Six founders were obtained; of these, four demonstrated germ line transmission. These lines were expanded by mating with C57BL/6 inbred mice. To achieve regionally selective expression in projection targets of mesencephalic dopaminergic systems, these monotransgenic mice were crossed with mice carrying a CaMKII $\alpha$-tTA transgene, as previously described (Mayford et al., 1996; Yamamoto et al., 2000) (Fig. 1B). These crosses revealed two BiTetO-LacZ-rGDNF lines, which, when crossed with the CaMKII-tTA line, produced positive LacZ staining in brain. Although this doubletransgene system permits suppression of transgene expression by administration of doxycycline (Fig. $1 B$ ), and we successfully demonstrated suppression in these two double-transgenic lines (data not shown), we did not use this feature in the studies presented herein. Before proceeding with an assessment of phenotype in living double-transgenic animals, we confirmed biological activity of the transgene rGDNF protein product by demonstrating that dissociated striatal postnatal cultures derived from double transgenics induced intense sprouting in cocultured postnatal mesencephalic DA neurons (Rayport et al., 1992) compared with wildtype striatal cultures (data not shown), an effect similar to that we had previously reported for exogenous GDNF (Burke et al., 1998).

LacZ staining and $\beta$-galactosidase immunohistochemistry. For LacZ staining, brains were removed rapidly and quickly frozen in isopentane on dry ice. Sections $14 \mu \mathrm{m}$ thick were cut in a cryostat, thaw-mounted on slides, and stored at $-80^{\circ} \mathrm{C}$. At the time of staining, the slides were warmed to room temperature, and the sections were fixed in $4 \%$ paraformaldehyde and $0.1 \mathrm{~m}$ phosphate buffer $(\mathrm{PB})$. After a rinse in PBS, sections were incubated in 5-bromo-4-chloro-3-indolyl $\beta$-Dgalactopyranoside staining solution as previously described (Yamamoto et al., 2000) at $37^{\circ} \mathrm{C}$ overnight. For demonstration of $\beta$-galactosidase expression at a cellular level, immunohistochemistry was performed. Animals were initially perfused by gravity intracardially with saline, followed by $4 \%$ paraformaldehyde and $0.1 \mathrm{M}$ PB. Brains were then postfixed in the same fixative for $24 \mathrm{hr}$ and then cryoprotected in $20 \%$ sucrose for an additional $24 \mathrm{hr}$ at $4^{\circ} \mathrm{C}$. The brains were then rapidly frozen in isopentane on dry ice, and sections were cut in a cryostat at $20 \mu \mathrm{m}$. Sections were processed free-floating. After a PBS wash and treatment with PBS, $0.5 \%$ bovine serum albumen, and $0.1 \%$ Triton X-100, sections were incubated with rabbit anti- $\beta$-galactosidase (Cortex-Biochem) at 1:500 for $48 \mathrm{hr}$ at $4^{\circ} \mathrm{C}$. After a wash, sections were then incubated biotinylated protein A (prepared in this laboratory) at 1:100 for $1 \mathrm{hr}$ at room temperature. Sections were then incubated with avidin-biotinylatedhorseradish peroxidase complexes (ABC; Vector Laboratories, Burlingame, CA) at 1:600 for $1 \mathrm{hr}$. After incubation with diaminobenzidine, sections were mounted onto subbed slides and counterstained with thionin.

Western analysis of GDNF, tyrosine hydroxylase, and vesicular monoamine transporter 2. Individual striata were homogenized in lysis buffer containing 50 mм Tris- $\mathrm{HCl}, \mathrm{pH}$ 7.5, $150 \mathrm{~mm} \mathrm{NaCl}, 2$ mм EDTA, 1\% NP-40, $5 \mu \mathrm{g} / \mathrm{ml}$ aprotinin, $5 \mu \mathrm{g} / \mathrm{ml}$ leupeptin, and $17 \mu \mathrm{g} / \mathrm{ml}$ PMSF. The homogenate was centrifuged at $14,000 \times g$ at $4^{\circ} \mathrm{C}$, and the protein concentration of the supernatant was determined with a micro BCA kit (Pierce, Rockford, IL). An aliquot containing 50-70 $\mu \mathrm{g}$ of protein/lane was diluted in Laemmli sample buffer (Bio-Rad, Hercules, CA), electrophoresed in a $15 \%$ polyacrylamide gel, and transferred onto a polyvinylidene difluoride (PVDF) membrane (Amersham Biosciences, Arlington Heights, IL). The membrane was then probed with anti-tyrosine hydroxylase (TH; Chemicon, Temecula, CA), anti-DA transporter (DAT; Chemicon), or anti-vesicular monoamine transporter 2 (VMAT2) (Chemicon) antibodies, treated with appropriate secondary antibodies, conjugated with horseradish peroxidase, and detected with a chemiluminescent substrate (Pierce). For Western analysis of GDNF, whole forebrain was homogenized in lysis buffer containing 1\% SDS and centrifuged, and the protein concentration of the supernatant was determined. An aliquot containing $100 \mu \mathrm{g}$ of protein was electrophoresed in a $15 \%$ polyacrylamide gel and transferred onto a PVDF membrane (Amersham Biosciences). The membrane was probed with anti-GDNF antibodies (Research Diagnostics, Inc., Flanders, NJ) and detected with chemiluminescent substrate.

Immunohistochemistry for TH in DA neurons of the SN. Animals were perfused intracardially first with $0.9 \% \mathrm{NaCl}$ and then with $4 \%$ paraformaldehyde and $0.1 \mathrm{M}$ PB. The brains were then removed and postfixed in 
the same fixative for 1 week. Each brain was then cryoprotected in $20 \%$ sucrose for $24-48 \mathrm{hr}$ and then rapidly frozen. A complete set of serial sections through the $\mathrm{SN}$ was then cut at $30 \mu \mathrm{m}$. Sections were saved individually in serial order at $4^{\circ} \mathrm{C}$, and individual sections at regular intervals were then selected for TH immunostaining, in conformity with the fractionator method of sampling (Coggeshall and Lekan, 1996) (see below). Sections were processed free-floating, as described above for $\beta$-galactosidase, with the exception that the primary antibody was a rabbit anti-TH (Calbiochem, La Jolla, CA) at 1:1000. After treatment with biotinylated protein $A$ and $A B C$, sections were mounted on subbed slides in serial order and thionin-counterstained.

Determination of SN and ventral tegmental area DA neuron numbers by stereological analysis. A complete set of TH-immunostained serial sections, sampled as every fourth section through the SN, was analyzed by a stereological method for each animal. Each analysis was performed under blinded conditions on coded slides. For each animal, the SN on one side of the brain was analyzed. For each section, the entire SN was identified as the region of interest. Using StereoInvestigator software (Micro Bright Field, Inc.) a fractionator probe was established for each section. The number of TH-positive neurons in each counting frame was then determined by focusing down through the section, using a $100 \times$ objective under oil, as required by the optical dissector method (Coggeshall and Lekan, 1996). Our criterion for counting an individual TH-positive neuron was the presence of its nucleus either within the counting frame or touching the right or top frame lines (green) but not touching the left or bottom lines (red). The total number of TH-positive neurons for each $\mathrm{SN}$ on one side was then determined by the StereoInvestigator program. The total volume of the $\mathrm{SN}$ was also determined by the StereoInvestigator program for each brain on the basis of the sum of volumes derived from the area of each individual serial section and the tissue height represented by that section. In a separate analysis of the same sections used for the SN determinations, the number of neurons in the ventral tegmental area (VTA) was determined.

Striatal TH fiber immunostaining and analysis. For optimal THpositive fiber staining, each mouse was perfused by a peristaltic pump at $10 \mathrm{ml} / \mathrm{min}$ intracardially with chilled $0.9 \% \mathrm{NaCl}$ for $3 \mathrm{~min}$, followed by chilled $4 \%$ paraformaldehyde and $0.1 \mathrm{M} \mathrm{PB}$ for $8 \mathrm{~min}$. Each brain was then postfixed in the same fixative for $48 \mathrm{hr}$ at $4^{\circ} \mathrm{C}$. Without cryoprotection, each brain was rapidly frozen in isopentane on dry ice. Coronal sections were then cut through the striatum at $30 \mu \mathrm{m}$ from planes $4.06-$ $4.90 \mathrm{~mm}$ (interaural; Paxinos and Franklin, 2001) and processed freefloating. After a wash in Tris-buffered saline (TBS) and treatment with TBS and $5 \%$ goat serum, sections were incubated with rabbit anti-TH (Calbiochem) at 1:500 for $48 \mathrm{hr}$ at $4^{\circ} \mathrm{C}$. Sections were then treated with biotinylated goat anti-rabbit antibody (Vector Laboratories) at 1:400 for $1 \mathrm{hr}$ at room temperature. They were then treated with $\mathrm{ABC}$ and incubated with diaminobenzidine. Sections were then mounted onto subbed slides and coverslipped. The regional optical density of TH immunostaining over the striatum was then determined as previously described (Burke et al., 1990). The optical density analysis was performed under blinded conditions on coded slides.

DAT immunostaining and stereological analysis. For DAT immunostaining, each animal was perfused by a pump at $20 \mathrm{ml} / \mathrm{min}$ intracardially with $0.1 \mathrm{M}$ PBS ( $1 \mathrm{U}$ of heparin $/ \mathrm{ml}$ ) at $37^{\circ} \mathrm{C}$ for $1.5 \mathrm{~min}$, followed by chilled $4 \%$ paraformaldehyde and $0.1 \mathrm{M} \mathrm{PB}$ by gravity for $5 \mathrm{~min}$, on the basis of the methods of Parish et al. (2001). The brain was then removed, blocked, and postfixed for $24 \mathrm{hr}$. Each brain was then cryoprotected in $20 \%$ sucrose for $24 \mathrm{hr}$ and then frozen rapidly in isopentane on dry ice. A complete set of serial sections through the striatum, from planes 3.944.90 (Paxinos and Franklin, 2001), was then cut at $30 \mu \mathrm{m}$. Sections were saved individually in serial order at $4^{\circ} \mathrm{C}$, and individual sections at regular intervals were processed for DAT immunostaining and stereological analysis. Sections were initially washed in TBS, treated with TBS and $0.1 \%$ Triton X-100, and blocked with $0.1 \mathrm{M}$ TBS and 3\% normal rabbit serum. After another TBS wash, they were incubated with rat anti-DAT (Chemicon) at 1:1000 in TBS and 3\% normal rabbit serum for $48 \mathrm{hr}$ at $4^{\circ} \mathrm{C}$. Sections were then treated with biotinylated rabbit anti-rat antibody (Vector Laboratories) at 1:300 for $1 \mathrm{hr}$ at room temperature. Sections were then treated with $\mathrm{ABC}$, incubated with diaminobenzidine, and mounted on subbed slides in serial order. The total number of DATpositive punctate structures in the striatum was then determined using a stereological approach, similar to that described by Parish et al. (2001). Every fifth section from planes $3.94-4.90$ was analyzed. For each section, the entire striatum on the one slide was identified as the region of interest. Using StereoInvestigator software, a fractionator probe was established. The number of DAT-positive punctate structures in each counting frame was then determined by focusing down through the section at $100 \times$ under oil. The total number of punctate structures per striatum and the striatal volume were determined by the StereoInvestigator program.

Measurement of striatal DA and metabolites. For determination of striatal levels of DA and its metabolites, mice were decapitated, and their brains were rapidly removed and placed into a chilled glass plate. Each brain was placed in mouse brain matrix, and a $2.0 \mathrm{~mm}$ coronal slice of forebrain was taken through the striatum. The slice was placed anterior surface-up on the glass plate, and the striatum was punched out on each side with a $2.0 \mathrm{~mm}$ punch. The striata were frozen on dry ice. For each pair of striata, DA, dihydroxyphenylacetic acid (DOPAC) and homovanillic acid (HVA) were determined by HPLC by Bioanalytical Systems Inc. and expressed as nanograms per sample.

Striatal slice preparation and electrochemical recordings. Striatal DA release was studied in five pairs of the double-transgenic mice and wildtype littermates for the adult group (2-5 months) and seven pairs for the PND 13-15 group using fast-scan cyclic voltammetry (CV). Recordings were obtained from the first three coronal slices $(300 \mu \mathrm{m})$ prepared from rostral caudate putamen. Slices were allowed to recover for $1.5 \mathrm{hr}$ in a holding chamber in oxygenated artificial CSF (ACSF) at room temperature and then placed in a recording chamber and superfused $(1 \mathrm{ml} / \mathrm{min})$ with ACSF (in mm: $125 \mathrm{NaCl}, 2.5 \mathrm{KCl}, 26 \mathrm{NaHCO}_{3}, 2.4 \mathrm{CaCl}_{2}, 1.3$ $\mathrm{MgSO}_{4}, 0.3 \mathrm{KH}_{2} \mathrm{PO}_{4}$, and 10 glucose) at $36^{\circ} \mathrm{C}$. Electrochemical recordings and electrical stimulation were adapted from the methods of Schmitz et al. (2001). Briefly, disk carbon fiber electrodes of $5 \mu \mathrm{m}$ diameter with a freshly cut surface were placed into the dorsal striatum $\sim 50$ $\mu \mathrm{m}$ into the slice. For $\mathrm{CV}$, a triangular voltage wave $(-400$ to $+900 \mathrm{mV}$ at $280 \mathrm{~V} / \mathrm{sec} \mathrm{vs} \mathrm{Ag} / \mathrm{AgCl}$ ) was applied to the electrode every $100 \mathrm{msec}$. Current was recorded with an Axopatch 200B amplifier (Axon Instruments, Foster City, CA), with a low-pass Bessel filter setting at $10 \mathrm{kHz}$, digitized at $25 \mathrm{kHz}$ (ITC-18 board; Instrutech Corp., Great Neck, NY). Triangular wave generation and data acquisition were controlled by a personal computer running a locally written IGOR program (Dr. Eugene Mosharov; WaveMetrics, Lake Oswego, OR). Striatal slices were electrically stimulated every 2 min with either a single-pulse stimulation or a paired stimulus by an Iso-Flex stimulus isolator triggered by a Master- 8 pulse generator (AMPI, Jerusalem, Israel) using a bipolar stimulating electrode placed at $\sim 100 \mu \mathrm{m}$ distance from the recording electrode. Background-subtracted cyclic voltammograms served to identify the released substance. The DA oxidation current was converted to concentration on the basis of a calibration of $5 \mu \mathrm{M}$ DA in ACSF after the experiment (Mosharov et al., 2003).

Behavioral analysis. Spontaneous motor activity in adult mice was assessed by use of a Med Associates, Inc. Activity Monitor System and expressed as distance traveled per $10 \mathrm{~min}$ epoch. Motor activity response to injection of amphetamine $(2.0 \mathrm{mg} / \mathrm{kg})$ was assessed in a separate group of animals by use of the following protocol: on day 1 , spontaneous motor activity over $2 \mathrm{hr}$ was assessed; and on days 2 and 3, motor activity was assessed over $2 \mathrm{hr}$ after administration of vehicle and amphetamine, respectively. Each animal was placed in the activity arena immediately after injection at time $=0$. For spontaneous motor activity, two-way ANOVA revealed no difference between males and females for either genotype, so data from males and females were combined.

\section{Results}

\section{Characterization of CaMKII $\alpha$-tTA $\times$ BiTetO-LacZ-rGDNF double-transgenic mice}

Of six founder lines of BiTetO-LacZ-rGDNF monotransgenic mice, two, lines 1 and 14, demonstrated positive LacZ staining in brain and increased forebrain GDNF protein expression when crossed with the CaMKII $\alpha$-tTA monotransgenic mice. Line 14 


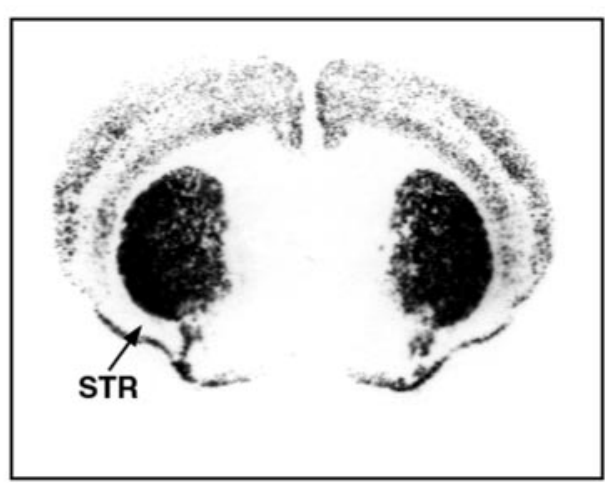

A
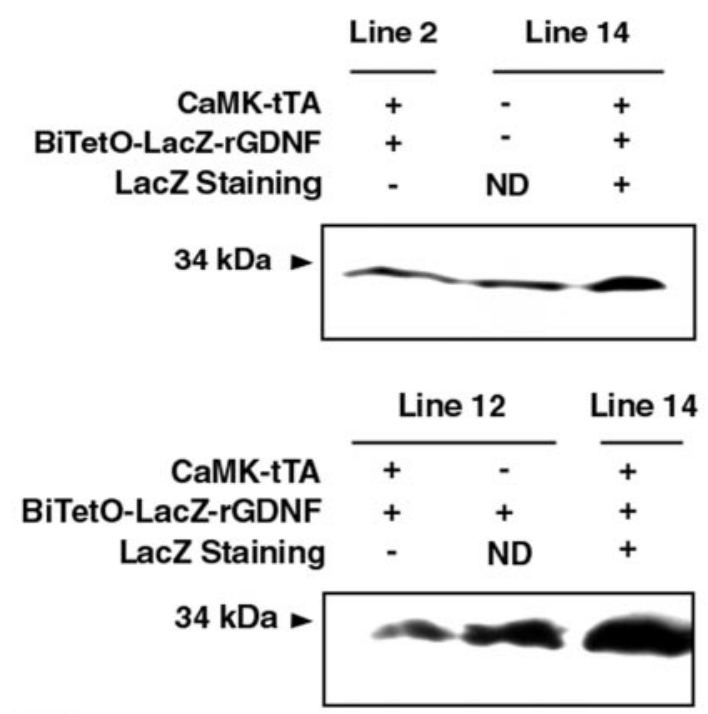

B

Figure 2. LacZ staining and GDNF expression in adult double-transgenic mice. A, LacZ staining in a coronal section through the striatum in a double transgenic mouse. The striatum (STR) is intensely positive for a reaction product. Staining is also observed in cortex, primarily in superficial and deep layers. $B$, Western analysis of GDNF expression in double-transgenic mice resulting from a cross of line 14 BiTet0-LacZ-rGDNF monotransgenic mice with CaMKII $\alpha$-tTA monotransgenic mice. In the top panel, more dimeric GDNF is present in forebrain in a doubletransgenic mouse than in a littermate wild-type control or in a double transgenic resulting from a line 2 founder cross, which lacked LacZ staining. In the bottom panel, a line 14 doubletransgenic mouse expresses more GDNF than a line 12 double-transgenic mouse that lacked LacZ staining or a line 12 BiTeto-LacZ-rGNDF monotransgenic control. The double transgenics express approximately twofold to threefold more GDNF in forebrain than controls. ND, Not determined.

showed the most robust LacZ staining in the striatum (Fig. 2), so it was selected for further studies. To confirm the regionally selective expression expected from the use of the CaMKII $\alpha$ promoter, representative sections in the rostrocaudal dimension were examined for LacZ staining. As anticipated, on the basis of previous use of the CaMKII $\alpha$-tTA mice by others (Mayford et al., 1996; Yamamoto et al., 2000), LacZ expression was observed in only select forebrain regions: striatum, hippocampus and cortex (Fig. 3). No LacZ expression was observed in brainstem regions

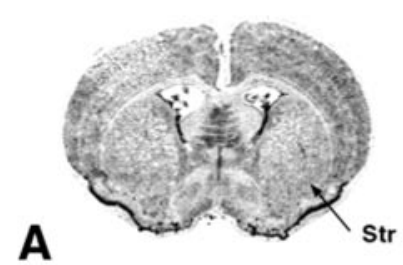

B
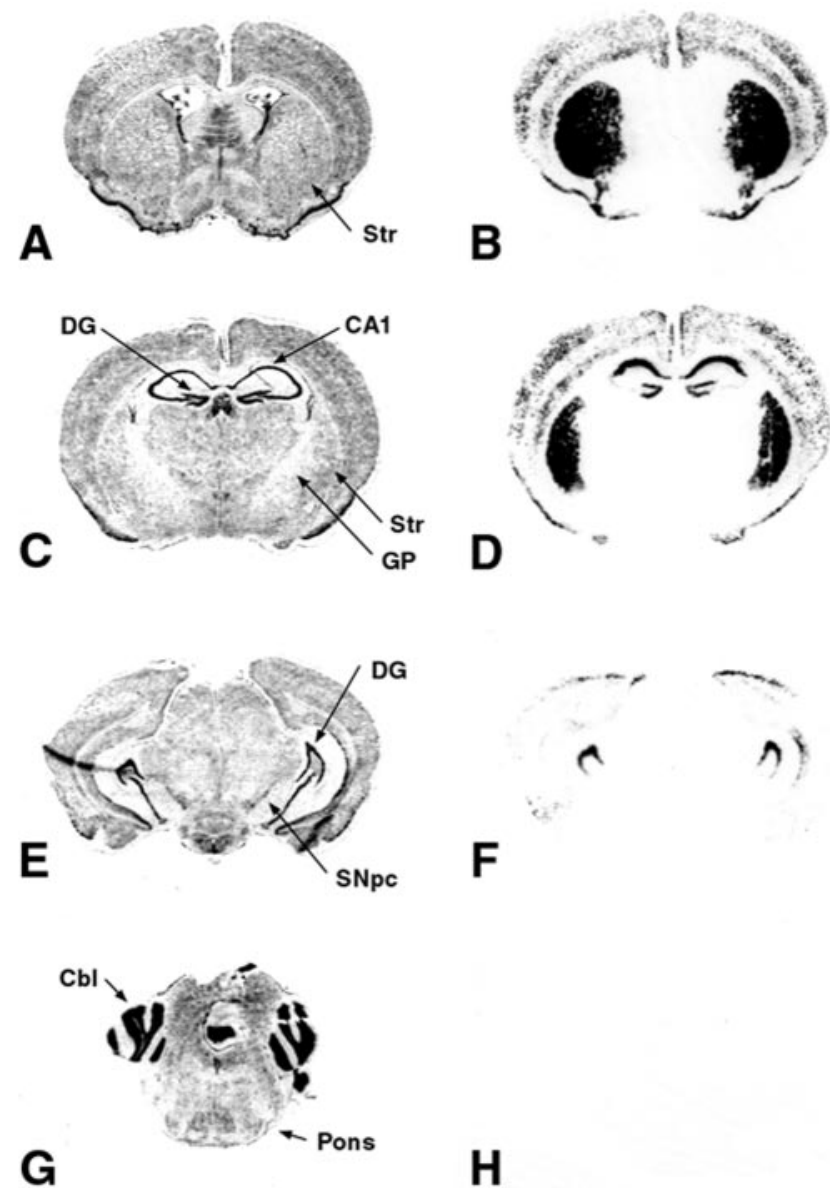

H

Figure 3. Regional patterns of LacZ expression in line 14 double transgenic mice. $A, C, E, G$, Nissl-stained coronal sections adjacent to the corresponding LacZ-stained sections shown in $B$, $D, F, H . A, B$, Correspond to anterior Paxinos and Franklin (2001) plane 4.06 (interaural); $C, D$, plane 2.46; $E$, $F$, plane $0.88 ; G, H$, most caudal, plane -1.22 . There is robust LacZ staining in striatum (Str), the CA1 region and the dentate gyrus (DG) of the hippocampus, and the cortex. There is no staining in the globus pallidus (GP), the SNpc, or the cerebellum (Cbl). Thus, LacZ expression is observed only in target regions of the mesencephalic dopaminergic projection.

that contain nuclei with afferent projections to the substantia nigra pars compacta (SNpc) (Carpenter, 1984), and, importantly, there was no LacZ expression in the SNpc itself. Among the forebrain targets of mesencephalic dopaminergic projection systems, the striatum showed the most intense LacZ staining. This pattern of more intense staining in striatum was observed in immature (2- and 4-week-old) mice (data not shown) as well as adults.

To confirm that forebrain GDNF is expressed at increased levels in double-transgenic mice throughout the postnatal period of natural cell death in SNpc DA neurons and thus would have the potential to influence it, we performed a developmental analysis. This analysis confirmed that double-transgenic mice did express higher levels of GDNF as early as PND 2 and until PND 14, the final day of the natural cell death event (Janec and Burke, 1993; Oo and Burke, 1997; Jackson-Lewis et al., 2000). Interestingly, for reasons that are unknown, the transgene protein product was observed principally as the monomeric form of GDNF during this developmental period. In our Western conditions, the monomer was not observed in controls (Fig. 4).

Little is known about the cellular sites of endogenous GDNF expression in developing or mature brain. However, limited data suggest that some of the expression in striatum during develop- 


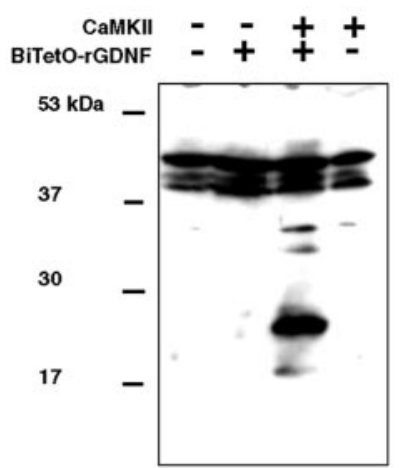

PND2
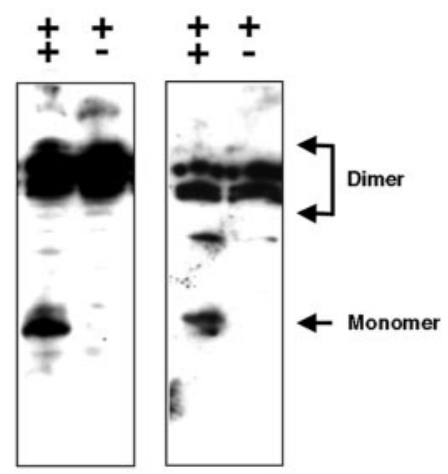

\section{PND6 PND14}

Figure 4. Developmental expression of forebrain GDNF in double-transgenic mice. Monomeric GDNF was demonstrable only in double-transgenic mice at PND 2,6, and 14 . The indicated controls were littermates at the indicated ages.

ment can be localized to neurons (Lopez-Martin et al., 1999). To determine whether transgene expression occurred in striatal neurons, we performed immunohistochemistry for $\beta$-galactosidase. This analysis revealed that, at a cellular level, transgene expression was confined to small striatal neurons, the major striatal population (Fig. 5). No expression was observed in large striatal neurons or non-neural cell types. This neuronal cellular pattern of expression is in keeping with the known expression patterns of CaMKII (Ouimet et al., 1984; Scholz et al., 1988). Thus, transgene expression occurs in a cellular population similar to that identified for endogenous GDNF (Lopez-Martin et al., 1999).

\section{SN DA neurons in CaMKII $\alpha$-tTA $\times$ BiTetO-LacZ-rGDNF double-transgenic mice}

To determine whether sustained overexpression of GDNF in the target regions of the mesencephalic dopaminergic system has an effect on the number of SN DA neurons surviving the first phase of natural cell death, we performed a stereological analysis on animals at PNDs 7-9, during the nadir of the first phase (Janec and Burke, 1993; Oo and Burke, 1997; Jackson-Lewis et al., 2000). This analysis revealed a $46 \%$ increase in the number of $\mathrm{TH}$ immunopositive neurons in the SN of CaMKII $\alpha$-tTA $\times$ BiTetOLacZ-rGDNF double-transgenic (CBLG-DT) mice compared with wild-type controls and a $77 \%$ increase compared with CaMKII $\alpha$-tTA monotransgenic controls (Fig. 6A). In addition to this increase in DA neuron number, there was also an increase in the mean DA neuron size in the double-transgenic animals (Fig. $6 B$, Table 1). A frequency histogram analysis of neuron sizes in the double-transgenic animals (data not shown) revealed that there was a shift of a normal distribution of sizes to larger; there was not the emergence of a bimodal distribution; i.e., no subsets of responsive and nonresponsive neurons were identifiable. There was no difference between wild-type and doubletransgenic animals in the mean size of the SN volume (Table 1).

To determine whether overexpression of GDNF throughout the development was sufficient to maintain an augmented number of neurons surviving into adulthood, we performed a stereological analysis of the number of SN DA neurons in animals aged 8-12 weeks (wild-type mean, $9.1 \pm 0.4$ weeks; CBLG-DT, $10.3 \pm$ $0.5)$. This analysis showed that, in adulthood, there was no longer any difference between wild-type and double-transgenic animals (Fig. 6C). In adulthood, both wild-type and double-transgenic

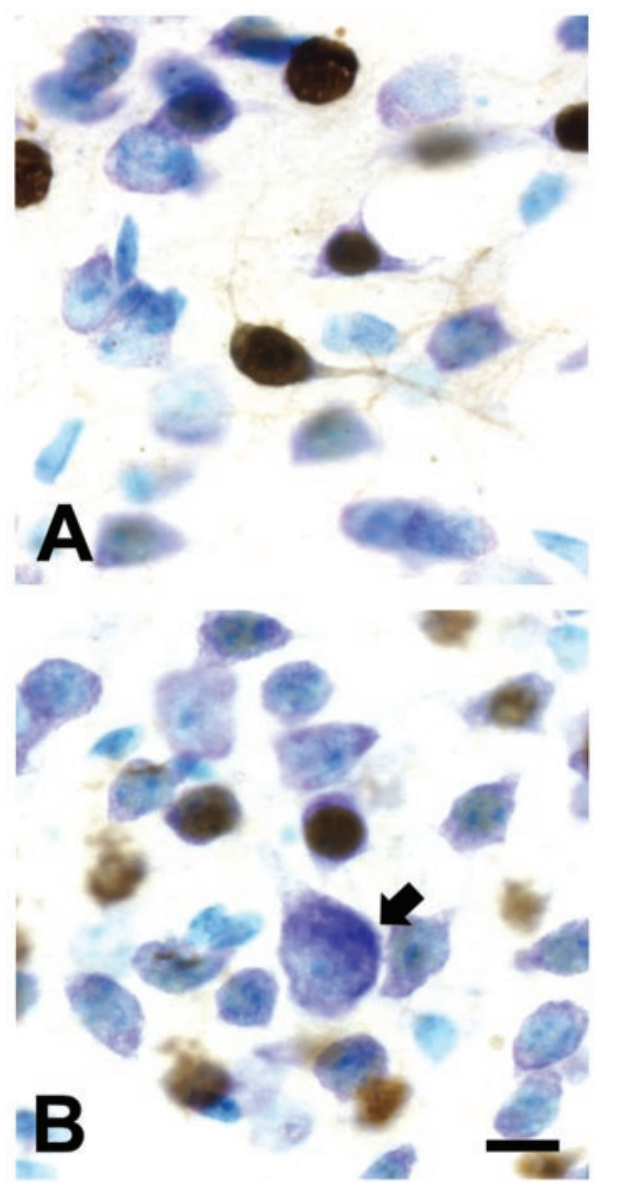

Figure 5. Transgene expression in small striatal neurons in double-transgenic animals. $A$, Immunoperoxidase staining for $\beta$-galactosidase with a Nissl counterstain reveals positive labeling of a number of small striatal neurons. The intense nuclear staining for $\beta$-galactosidase is attributable to the incorporation of a nuclear localization signal within the sequence. B, Staining was not observed in large striatal neurons (arrow) or non-neuronal cells (results not shown). Scale bar, $10 \mu \mathrm{m}$.

animals had approximately the same estimated total number of SN DA neurons as observed in wild-type and monotransgenic controls after the first phase of the natural cell death. There was also no difference between wild-type and CBLG-DT adult mice in the size of their DA neurons or the volume of the SNs (Table 1). Unlike the SN, the VTA showed an increase in the number of DA neurons in adult double-transgenic animals, to 55\% more than that of wild-type controls (Fig. 6D).

We considered the possibility that the decrease in the relative numbers of the SN DA neurons in the double-transgenic animals between PNDs 7-9 and adulthood may be attributable to the inability of overexpressed GDNF to maintain an augmented population through the second phase of natural cell death at PND 14, when perhaps some other factor becomes limiting and results in a "rebound" increase in natural cell death in the double transgenics. To assess this possibility, we determined the number of apoptotic profiles in SN in PND 14-15 animals. We found that there was no rebound increase in natural cell death among the double transgenics; on the contrary, they showed a diminished level of apoptosis in comparison with a group including wild-type and CaMKII-tTA monotransgenic controls: controls $(n=16), 3.9 \pm$ 0.4 apoptotic profiles per SN; CBLT-DT $(n=13), 2.9 \pm 0.3(p=$ $0.05, t$ test). Thus, the normalization of SN DA neuron numbers in the double-transgenic mice does not occur within the time 


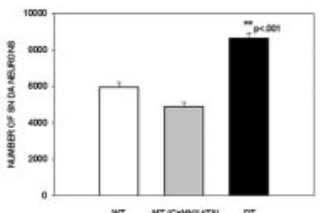

A SN DA NEURONS: PND 7-9

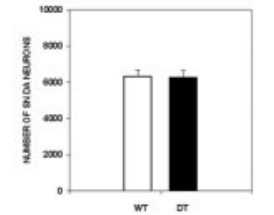

C SN DANEURONS: ADULTS

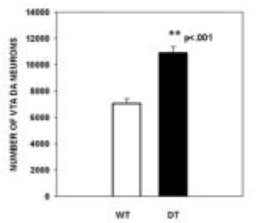

D VTA DA NEURONS: ADULTS
B

Figure 6. SN and VTA DA neuron numbers in CBLG-DT and control mice after the first phase of natural cell death and in adulthood. A, At PNDs 7-9, at the nadir of cell death after the first phase, there is a $46 \%$ increase in the total number of SN DA neurons in double transgenic (DT) animals $(n=14)$ compared with WT controls ( $n=16$; ${ }^{* *} p<0.001$, ANOVA). There was also an increase in comparison with CaMKII-tTA monotransgenic (MT) controls $(n=8)$. For this analysis, CBLG-DT mice were always analyzed in parallel with littermate controls. $B$, Representative SN DA neurons at PND 7 revealing a typical example of the size difference between DA neurons in WT and DT animals. Neurons have been immunoperoxidase stained for TH. Scale bar, $10 \mu \mathrm{m}$. C, In adult animals, there was no longer a difference between double-transgenic and wild-type animals in the total number of SN DA neurons ( $n=8$, both groups). $D$, In adult animals, there was a 55\% increase in the number of VTA DA neurons in double-transgenic animals compared with wild-type controls. The sections used for this analysis were the same as those used for the SN analysis shown in C.

course of the normal natural cell death event in these neurons during the first 2 postnatal weeks.

\section{Striatal dopaminergic innervation is not increased in CBLG-DT mice}

Although sustained GDNF overexpression in mesencephalic dopaminergic target regions did not induce a lasting increase in the number of SN dopaminergic neurons, in light of the ability of exogenous GDNF to induce sprouting of dopaminergic fibers in adult animals of different species (Hudson et al., 1995; Tomac et al., 1995a; Kordower et al., 2000), we sought to evaluate the possibility that the double-transgenic animals may show increased dopaminergic innervation of the striatum. However, the striatal TH-positive fiber staining evaluated at the regional level by optical density measurements (Burke et al., 1990; Oo et al., 2003) in adult mice revealed no difference between double transgenics and controls (Fig. 7A), nor did Western analysis of TH in striata (Fig. 7B). We considered the possibility that GDNF overexpression may downregulate the expression of $\mathrm{TH}$ as a phenotypic marker of dopaminergic structures because it has been shown to do so when overexpressed by lentiviral transfer (Georgievska et al., 2002). We therefore used another marker, that of DAT, to assess dopaminergic innervation at a cellular level. We assessed the number of DAT-positive punctate structures within the entire striatum by use of a stereological technique, as previously described (Parish et al., 2001). This analysis likewise did not reveal a difference between CBLG-DT mice and wild-type controls (Fig. 7C). There was also no difference between doubletransgenic mice and controls in either the volume of the striatum or the density of DAT-positive punctate structures (data not shown).

In addition to these assessments of protein phenotypic markers of dopaminergic fibers and terminals, we assayed by HPLC striatal DA and its metabolites, DOPAC and HVA. These measures, as well as calculation of the DOPAC/DA ratio, revealed no difference between double-transgenic mice and both monotransgenic and wild-type controls (Fig. 7D; data not shown).

Although these morphological and biochemical assessments showed no effect on dopaminergic striatal innervation in the double-transgenic mice, we considered the additional possibility that there may be effects detectable by physiological assessments. We therefore examined DA release in the striatum by using electrochemical recordings. Striatal slice preparations containing presynaptic DA terminals were stimulated by a single electrical pulse, and the concentration and kinetics of DA release were measured using fast-scan CV (Wightman and Zimmerman, 1990). Because PND 14 is a critical period for dopaminergic development (Janec and Burke, 1993), we investigated the evoked DA release in PND 13-15 mice in addition to the adult mice. To minimize the variations of evoked DA release attributable to the heterogeneous distribution of the DA terminals, three sites in the dorsal striatal region of each slice were checked and then averaged. Although evoked DA release in PND 13-15 mice [wild-type (WT), $1.49 \pm 0.17 \mu \mathrm{M} ; n=16$; CBLG-DT, $1.38 \pm 0.15 \mu \mathrm{M} ; n=$ 11] was smaller compared with that in adult (WT, $2.23 \pm 0.28$ $\mu \mathrm{M} ; n=16$; CBLG-DT, $2.34 \pm 0.29 \mu \mathrm{M} ; n=11$ ), consistent with the immaturity of the DA system, DA release in response to a single-pulse stimulus did not differ significantly between transgenic and WT mice either at PND 13-15 (data not shown) or at the age of adult (Fig. 8A).

Evoked DA release in striatal slices exhibits a pronounced and long-lasting paired pulse depression (PPD); i.e., the amount of DA release elicited by the second stimulus is reduced compared with the DA release elicited by the first stimulus. Full recovery takes $\sim 60 \mathrm{sec}$ and is fitted by a double-exponential function (Kennedy et al., 1992; Abeliovich et al., 2000). Therefore, to investigate whether GDNF overexpression in the transgenic mice plays a role in modulation of the activity-dependent synaptic DA release, we examined the PPD both in the adult and the PND 13-15 groups. Slices were stimulated with a paired pulse at interpulse intervals ranging from 1 to $60 \mathrm{sec}$ (Fig. $8 \mathrm{~B}$ ). In adult WT mice, the time constants for the fast component $(\tau \mathrm{f})$ and the slow component $(\tau \mathrm{s})$ were 4.2 and $16.4 \mathrm{sec}$, respectively, whereas in adult CBLG-DT mice, $\tau \mathrm{f}$ and $\tau \mathrm{s}$ were 4.4 and $18.5 \mathrm{sec}$. Thus, the results indicated that overexpression of GDNF in the transgenic mice did not alter the kinetics of DA transmission. The same conclusion applied to the PND 13-15 group (data not shown), although at the interval of $5 \mathrm{sec}$, we observed a slightly faster recovery of the DA release in the transgenic mice.

We therefore conclude that overexpression of GDNF in striatum throughout development, at the levels achieved in these double-transgenic mice, is not sufficient to induce a lasting dopaminergic hyperinnervation by morphological, biochemical, or physiological criteria.

\section{Cortical dopaminergic innervation is increased in CBLG-DT mice}

Given our finding of increased numbers of VTA DA neurons in the CBLG-DT adult mice and the important differences in the neurobiology of the nigrostriatal and mesocortical dopaminergic projections (Mundorf et al., 2001), we next sought to determine whether GDNF overexpression had an effect on cortical innervation by dopaminergic fibers. In the same DAT-immunostained sections used for the analysis of the striatum, we used a stereological optical fractionator technique to determine the number of DAT-positive structures in the piriform cortex, where there is 
Table 1. Morphometric analysis of DA neuron areas and SN volumes in CBLG-DT and WT mice

\begin{tabular}{|c|c|c|c|c|c|c|}
\hline \multirow[b]{2}{*}{ Genotype } & \multicolumn{3}{|c|}{ PND 7-9 } & \multicolumn{3}{|c|}{ Adult } \\
\hline & $\bar{n}$ & Cell area $\left(\mu \mathrm{m}^{3}\right)$ & SN volume $\left(\mu \mathrm{m}^{3} \times 10^{6}\right)$ & $\bar{n}$ & Cell area $\left(\mu \mathrm{m}^{3}\right)$ & SN volume $\left(\mu \mathrm{m}^{3} \times 10^{6}\right)$ \\
\hline WT & 7 & $232 \pm 6.3$ & $555 \pm 33$ & 8 & $185 \pm 5.4$ & $739 \pm 25$ \\
\hline CBLG-DT & 7 & $370 \pm 11.1^{*}$ & $616 \pm 26$ & 8 & $191 \pm 5.8$ & $778 \pm 37$ \\
\hline
\end{tabular}

At PNDs 7-9, DA neurons were significantly larger in double-transgenic mice. There was no difference in SN volume. In adult animals, there was no difference in either neuron size or SN volume. ${ }^{*} p<0.001$.
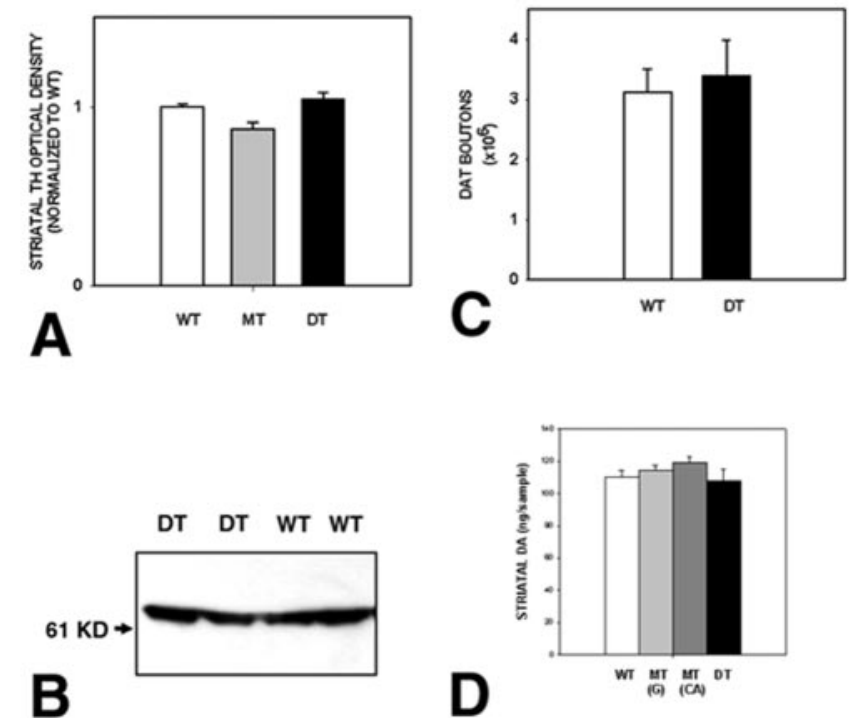

Figure 7. Assessment of striatal measures of dopaminergic innervation in adult CBLG-DT mice. $A$, Measurement of the optical density of TH-positive fiber immunostaining in striatal coronal sections revealed no differences between double-transgenic (DT) mice and WT and BiTet0-LacZ-rGDNF monotransgenic (MT) controls in adults ( $n=3$ animals per group, 4-5 sections per animal). $B$, Western analysis of TH expression in striatal micropunch-dissected tissue revealed no difference between double-transgenic and wild-type mice. C, Stereological assessment of the numbers of DAT-positive punctate structures in complete sets of serial striatal sections using the optical fractionator probe demonstrated no difference between adult double-transgenic and wild-type mice ( $n=6$, each group). D, Measurement of striatal DA by $H P L C$ revealed no differences between double-transgenic mice and wild-type and monotransgenic controls (G, BiTet0-LacZ-rGDNF monotransgene; CA, CaMKIII $\alpha$-TTA monotransgene; $n=$ 8 , each group).

normally a high density of DA terminals (Bjorklund and Lindvall, 1984). This analysis revealed a 2.8 -fold increase in the number of DAT-positive puncta in double-transgenic mice compared with wild-type controls (Fig. 9A-C). We did not attempt to measure the average length of DAT-positive fibers in these sections, but visual inspection demonstrated much more extended and branched fiber networks in the double-transgenic mice (Fig. $9 A, B)$. To confirm this observation with another phenotypic marker for dopaminergic fibers, we used the same sections used for analysis of striatal TH immunostaining to quantify the number TH-positive fibers entering the cingulate cortex from the corpus callosum. This specific anatomical location also normally contains a high density of dopaminergic fibers, and it is advantageous methodologically because individual fibers can be discerned and counted. This analysis also revealed an increase, by $40 \%$, in the double-transgenic mice compared with wild-type mice. We conclude that, in the cortex, unlike the striatum, there is an increase in dopaminergic innervation.

\section{Basal and amphetamine-induced activity in CBLG-DT mice}

To determine whether these morphologic demonstrations of increased cortical dopaminergic innervation in the double-

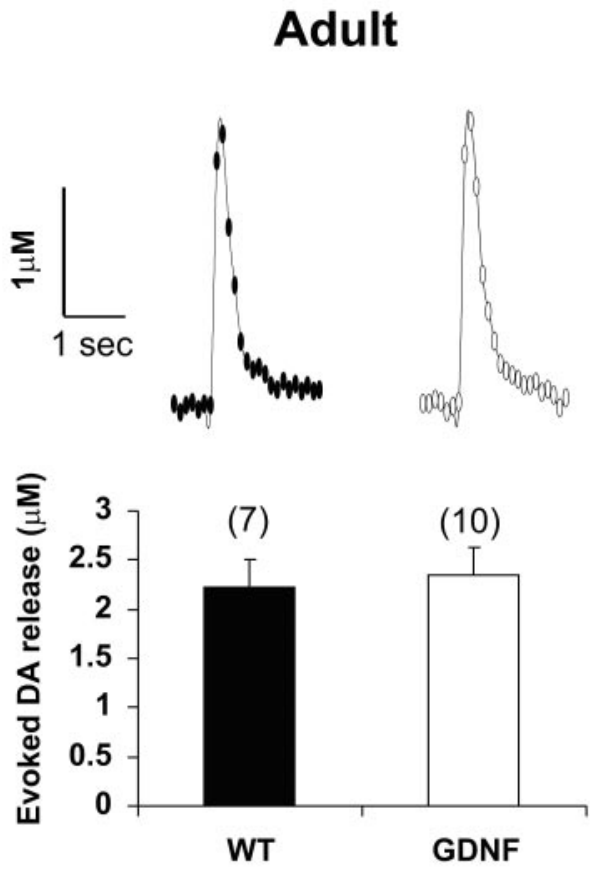

A

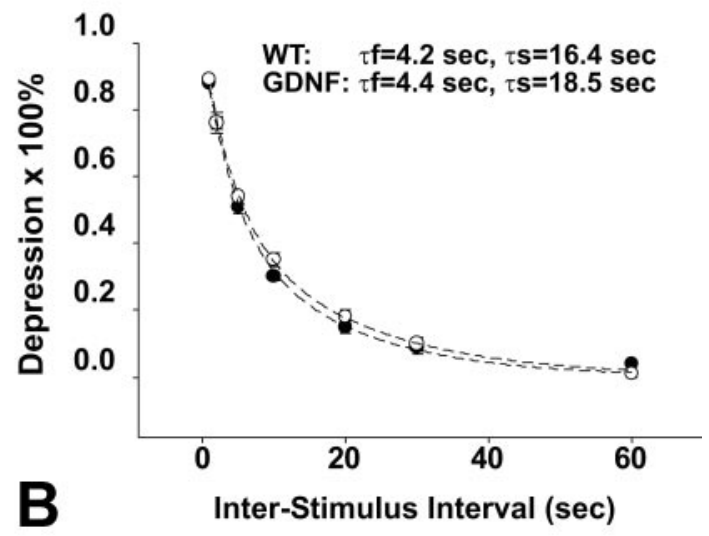

Figure 8. Electrically evoked DA release in striatal slice preparations was measured using fast-scan CV. A, Representative $\mathrm{CV}$ recording traces in response to a single pulse stimulus and the averaged peak $D A$ responses. DA release in response to a single pulse stimulus did not differ significantly between genotypes in adult animals or in pups at PND 13-15 (data not shown). The numbers of slices for the paired group (WT, filled bar; CBLG-DT, open bar) are indicated in parentheses. $B$, Paired pulse depression was not altered in CBLG-DT mice. Paired electrical stimuli were applied at variable interpulse intervals $(1,2,5,10,20,30$, and $60 \mathrm{sec})$. Average time courses for recovery of the peak DA response are presented as percent depression of the second stimulus response relative to the first [ $100 \times(1$ sec peak amplitude/first peak amplitude)] in WT and CBLG-DT mice ( 5 slices each from 5 pairs of the adult group). Data were fitted by double-exponential functions (dashed lines) in the form of $y=0.5 \times \exp (-t / \tau f)+0.5 \times$ $\exp (-\mathrm{t} / \tau \mathrm{s})$. 


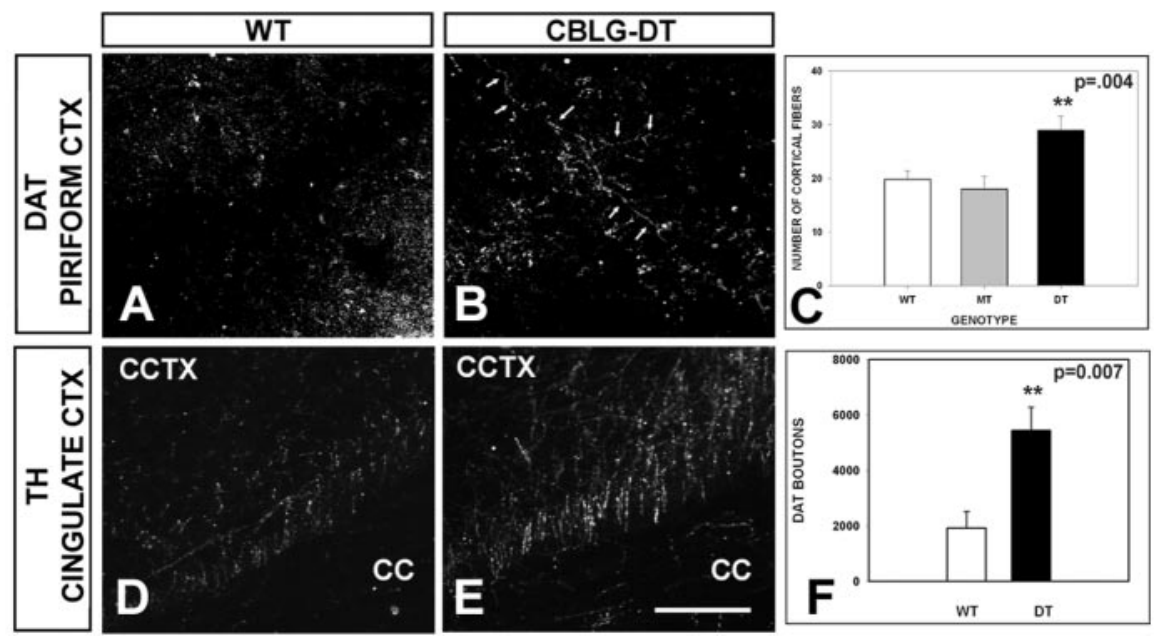

Figure 9. Cortical dopaminergic innervation in CBLG-DT mice. $A, B$, Representative examples of DAT immunostaining in piriform cortex in a double-transgenic animal $(B)$ in comparison with a wild-type animal $(A)$. In the double-transgenic animal, there are many more extended and branched DAT-positive fibers (arrows). By stereological analysis, there are also more DATpositive boutons in the cortex of double-transgenic (DT) animals $(C ; n=6$, each group; $p=0.007)$. D, E, Representative examples of TH immunostaining of fibers entering the cingulate cortex (CCTX) from the corpus callosum (CC) in a double-transgenic animal $(E)$ in comparison with a wild-type animal $(D)$. Quantitative analysis confirmed that TH-positive fibers were more numerous in DT mice compared with WT and BiTet0-LacZ-rGDNF monotransgenic (MT) mice ( $n=3$, each group; $p=0.004$, ANOVA). Scale bar, $100 \mu \mathrm{m}$

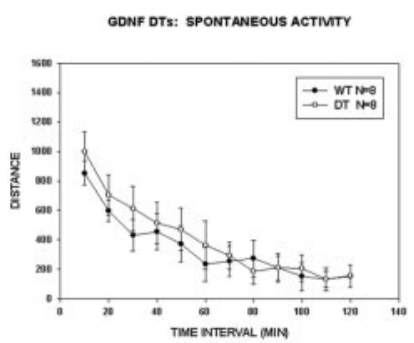

A

Figure 10. Spontaneous and amphetamine-induced activity in CBLG-DT mice. A, Spontaneous activity in an open field was not different between double-transgenic (DT) and wild-type mice. Two-way repeated measures ANOVA revealed a significant effect of time, with the animals being significantly more active during the first 40 min of observation, but there was no genotype effect. $B$, After injection of amphetamine, there was a significant induction of activity by amphetamine for both groups, as expected ( $p<0.001$, ANOVA). There was also a genotype effect, with a higher level of induction of activity in the double transgenics during the first 40 min of observation.

transgenic mice may have a behavioral correlate, we examined basal and amphetamine-induced activity in an open-field setting. This analysis revealed no difference between double-transgenic and wild-type animals in basal activity in an open field, monitored for $120 \mathrm{~min}$ (Fig. 10 A). However, in response to amphetamine $(2.0 \mathrm{mg} / \mathrm{kg})$, double-transgenic mice showed increased activity for the initial 40 min of observation (Fig. $10 \mathrm{~B}$ ).

\section{Discussion}

One principal result of these investigations is the demonstration that sustained developmental overexpression of GDNF in the striatum, the primary target of the dopaminergic nigrostriatal projection, results in an increased surviving number of DA neurons after the first phase of natural cell death. This result supports the hypothesis that GDNF serves as a physiological, limiting, striatum-derived neurotrophic factor for DA neurons during their first phase of natural cell death. This hypothesis is further supported by a number of previous observations. GDNF mRNA is highly expressed in the striatum during development (Schaar et al., 1993; Stromberg et al., 1993; Blum and Weickert, 1995; Choi-Lundberg and Bohn, 1995; Golden et al., 1999), and we have shown by quantitative analysis that its highest level of expression is on PND 2 (Cho et al., 2003), during the first phase. The receptor for GDNF, GDNF receptor $\alpha 1$ (GFR $\alpha 1)$, and its signaling tyrosine kinase, Ret, are both highly expressed in SNpc during development (Widenfalk et al., 1997; Yu et al., 1998). As expected for a target-derived factor, GDNF can be specifically transported retrograde from striatum to $\mathrm{SNpc}$ (Tomac et al., 1995b). We showed that GDNF uniquely suppressed apoptosis specifically within DA neurons in a primary postnatal culture model established during the first phase of natural cell death (Burke et al., 1998). In vivo, GDNF administered into the striatal target on PND 2 suppresses natural cell death (Oo et al., 2003). Conversely, anti-GDNF neutralizing antibodies administered into the striatum augment death, but they are only capable of doing so during the first phase (Oo et al., 2003). The chief evidence against a physiological role for GDNF in regulating natural cell death in substantia nigra DA neurons is that homozygous null mice for GDNF (Moore et al., 1996; Pichel et al., 1996; Sanchez et al., 1996) and for GFR $\alpha 1$ (Cacalano et al., 1998; Enomoto et al., 1998) show no reduction in the number of DA neurons at birth. However, these mutations are perinatal lethal because of abnormalities of the kidneys and the enteric nervous system, so the mice die before most of the postnatal natural cell death event has occurred. Furthermore, these were not temporally regulated nulls, so compensatory changes may have taken place. Further studies in regionally specific and temporally regulated nulls are required to resolve these issues. In summary, we conclude that, at the present time, the weight of the evidence supports a physiological role for GDNF in regulating the first phase of natural cell death in DA neurons.

The question may be raised of whether the increased number of TH-positive DA neurons at PNDs 7-9, demonstrated by immunohistochemistry, represents an increase in phenotypic expression rather than an actual increase in the number of surviving neurons. This explanation is unlikely because we have previously shown for PND 2 animals (Oo et al., 2003) and in the current study for PND 14-15 animals that increased levels of striatal GDNF suppress apoptosis. In addition, an effect solely on phenotype cannot explain our observation of a higher number of DA neurons at PNDs 7-9 in the double transgenics than in adults of either the wild-type or double-transgenic genotype.

Although increased striatal GDNF expression is sufficient to augment the number of SN DA neurons surviving after the first phase of natural cell death, we find that it is not sufficient to maintain an increased number of these neurons surviving into adulthood. We considered the possibility that, in the absence of increased abundance of some other unknown factor(s) during the second phase of natural cell death at PND 14, there may be a rebound increased level of natural cell death in the double transgenics at that time, but we found this not to be the case. In fact, we 
continued to observe a modest suppression of cell death in the double-transgenic animals at PND 14. We assume, therefore, that sometime between PND 14 and adulthood, the numbers of DA neurons in the double transgenics diminish to wild-type levels. The timing and mechanism of this regressive event are unknown, and also unknown are the other factors that participate with GDNF in the regulation of the ultimate adult number of DA neurons. These factors may include other target-derived diffusible factors or the GDNF receptor GFR $\alpha 1$, which may become limiting in the double-transgenic animals, or they may include afferent projections, which have been shown to regulate DA neuron number (Alonso-Vanegas et al., 1999).

An unexpected observation, in view of previous demonstrations in lesion models of the ability of GDNF to induce dopaminergic fiber sprouting when injected intracerebrally (Hudson et al., 1995; Tomac et al., 1995a; Rosenblad et al., 1998), was the lack of an effect in double-transgenic animals on striatal dopaminergic innervation or evoked DA release. We considered the possibility that GDNF overexpression attributable to the transgenes may have been downregulated TH expression, as described when GDNF overexpression is mediated by lentiviral gene transfer (Georgievska et al., 2002). However, assessment of DAT immunostaining at the cellular level and VMAT2 protein levels by Western analysis (data not shown) also failed to provide evidence of hyperinnervation. This lack of an effect on striatal dopaminergic innervation was observed despite a clear induction of innervation in the adjacent cortex, demonstrated as increased numbers of DAT-positive fibers in piriform cortex and TH-positive fibers in cingulate cortex. This difference in effects on striatal and cortical innervation is not likely to be attributable to differences in the level of GDNF expression between the two target regions. In fact, striatum is more likely to express higher levels of GDNF because it showed higher levels of $\beta$-galactosidase expression throughout development. It has been shown that $\beta$-galactosidase expression strongly predicts levels of expression of the second transgene in this bicistronic, bidirectional module (Krestel et al., 2001). The increased dopaminergic cortical innervation correlates with our finding that, in the VTA, which gives rise to the cortical innervation, there is an increased adult number of DA neurons in the double transgenic animals. These results therefore may suggest a fundamental difference in the responsiveness of the mesocortical and nigrostriatal systems to GDNF. These results may indicate, for example, that nigrostriatal dopaminergic innervation, unlike mesocortical dopaminergic innervation, is limited by some factor other than, or in addition to, GDNF. One possibility is that striatal GFR $\alpha 1$, exerting an effect in trans (Yu et al., 1998; Paratcha et al., 2001), becomes limiting in the doubletransgenic animals. Such an effect has been demonstrated in vitro for neurite growth of nodose and sympathetic ganglia grown in the presence of nonlimiting concentrations of GDNF (Ledda et al., 2002).

Despite our inability to demonstrate increased dopaminergic innervation or DA release in the striatum in the CBLG-DT animals, we observed a behavioral phenotype of increased locomotor activity after administration of amphetamine. This behavioral response has classically been attributed to an induction of striatal DA release by amphetamine (Schultz, 1982; Weiner, 1985). Thus, the presence of this behavioral phenotype may therefore suggest that developmental overexpression of GDNF in the striatal target has had a lasting functional effect on the nigrostriatal dopaminergic projection not assessed by the physiological studies that we performed. Further experiments, for example, examining the DA release challenged with amphetamine, will shed light on the un- derlying mechanism. Alternatively, it is also possible that the increased locomotor response to amphetamine in the doubletransgenic animals is not related to the nigrostriatal projection but rather to the dopaminergic mesocortical projection, which is clearly increased by morphologic analysis. Unfortunately, investigation of DA transmission in the cortex by $\mathrm{CV}$ in vitro was hindered by the sparse innervations of DA terminals in this region. Thus, these CBLG-DT animals may prove useful for the functional analysis of dopaminergic mesencephalic projections.

In conclusion, the present findings lend further support to the hypothesis that striatal target-derived GDNF plays a physiological role in the early determination of numbers of SN DA neurons. It is also clear, however, that GDNF alone in target structures is not sufficient to produce a lasting increase in the mature number of these neurons, so other regulatory factors remain to be identified.

\section{References}

Abeliovich A, Schmitz Y, Farinas I, Choi-Lundberg D, Ho WH, Castillo PE, Shinsky N, Verdugo JM, Armanini M, Ryan A, Hynes M, Phillips H, Sulzer D, Rosenthal A (2000) Mice lacking alpha-synuclein display functional deficits in the nigrostriatal dopamine system. Neuron 25:239-252.

Alonso-Vanegas MA, Fawcett JP, Causing CG, Miller FD, Sadikot AF (1999) Characterization of dopaminergic midbrain neurons in a DBH:BDNF transgenic mouse. J Comp Neurol 413:449-462.

Barde YA (1989) Trophic factors and neuronal survival. Neuron 2:1525-1534.

Baron U, Freundlieb S, Gossen M, Bujard H (1995) Co-regulation of two gene activities by tetracycline via a bidirectional promoter. Nucleic Acids Res 23:3605-3606.

Bjorklund A, Lindvall O (1984) Dopamine-containing systems in the CNS. In: Handbook of chemical neuroanatomy (Bjorklund A, Hokfelt T, eds), pp 55-122. Amsterdam: Elsevier.

Blum M, Weickert CS (1995) GDNF mRNA expression in normal postnatal development, aging, and in weaver mutant mice. Neurobiol Aging 16:925-929.

Bowenkamp KE, Hoffman AF, Gerhardt GA, Henry MA, Biddle PT, Hoffer BJ, Granholm A-CE (1995) Glial cell line-derived neurotrophic factor supports survival of injured midbrain dopaminergic neurons. J Comp Neurol 355:479-489.

Burke RE, Cadet JL, Kent JD, Karanas AL, Jackson Lewis V (1990) An assessment of the validity of densitometric measures of striatal tyrosine hydroxylase-positive fibers: relationship to apomorphine-induced rotations in 6-hydroxydopamine lesioned rats. J Neurosci Methods 35:63-73.

Burke RE, Antonelli M, Sulzer D (1998) Glial cell line-derived neurotrophic growth factor inhibits apoptotic death of postnatal substantia nigra dopamine neurons in primary culture. J Neurochem 71:517-525.

Cacalano G, Farinas I, Wang LC, Hagler K, Forgie A, Moore M, Armanini M, Phillips H, Ryan AM, Reichardt LF, Hynes M, Davies A, Rosenthal A (1998) GFRalphal is an essential receptor component for GDNF in the developing nervous system and kidney. Neuron 21:53-62.

Carpenter MB (1984) Interconnections between the corpus striatum and brain stem nuclei. In: The basal ganglia (McKenzie JS, Kemm RE, Wilcock LN, eds), pp 1-68. Bethesda, MD: Plenum.

Cho J, Kholodilov NG, Burke RE (2003) The developmental time course of glial cell line-derived neurotrophic factor (GDNF) and GDNF receptor alpha-1 mRNA expression in the striatum and substantia nigra. Ann NY Acad Sci 991:284-287.

Choi-Lundberg DL, Bohn MC (1995) Ontogeny and distribution of glial cell line-derived neurotrophic factor (GDNF) mRNA in rat. Brain Res Dev Brain Res 85:80-88.

Choi-Lundberg DL, Lin Q, Chang YN, Chiang YL, Hay CM, Mohajeri H, Davidson BL, Bohn MC (1997) Dopaminergic neurons protected from degeneration by GDNF gene therapy. Science 275:838-841.

Chun HS, Yoo MS, DeGiorgio LA, Volpe BT, Peng D, Baker H, Peng C, Son JH (2002) Marked dopaminergic cell loss subsequent to developmental, intranigral expression of glial cell line-derived neurotrophic factor. Exp Neurol 173:235-244. 
Clarke PGH (1985) Neuronal death in the development of the vertebrate nervous system. Trends Neurosci 8:345-349.

Coggeshall RE, Lekan HA (1996) Methods for determining numbers of cells and synapses: a case for more uniform standards of review. J Comp Neurol 364:6-15.

El-Khodor BF, Burke RE (2002) Medial forebrain bundle axotomy during development induces apoptosis in dopamine neurons of the substantia nigra and activation of caspases in their degenerating axons. J Comp Neurol 452:65-79.

Enomoto H, Araki T, Jackman A, Heuckeroth RO, Snider WD, Johnson EMJ, Milbrandt J (1998) GFR alphal-deficient mice have deficits in the enteric nervous system and kidneys. Neuron 21:317-324.

Gash DM, Zhang ZM, Ovadia A, Cass WA, Yi A, Simmerman L, Russell D, Martin D, Lapchak PA, Collins F, Hoffer BJ, Gerhardt GA (1996) Functional recovery in parkinsonian monkeys treated with GDNF. Nature 380:252-255.

Georgievska B, Kirik D, Bjorklund A (2002) Aberrant sprouting and downregulation of tyrosine hydroxylase in lesioned nigrostriatal dopamine neurons induced by long-lasting overexpression of glial cell line derived neurotrophic factor in the striatum by lentiviral gene transfer. Exp Neurol 177:461-474.

Gill SS, Patel NK, Hotton GR, O’Sullivan K, McCarter R, Bunnage M, Brooks DJ, Svendsen CN, Heywood P (2003) Direct brain infusion of glial cell line-derived neurotrophic factor in Parkinson disease. Nat Med 9:589-595.

Golden JP, DeMaro JA, Osborne PA, Milbrandt J, Johnson EMJ (1999) Expression of neurturin, GDNF, and GDNF family-receptor mRNA in the developing and mature mouse. Exp Neurol 158:504-528.

Groc L, Bezin L, Foster JA, Jiang H, Jackson TS, Weissmann D, Levine RA (2001a) Lipid peroxidation-mediated oxidative stress and dopamine neuronal apoptosis in the substantia nigra during development. Neurochem Int 39:127-133.

Groc L, Bezin L, Jiang H, Jackson TS, Levine RA (2001b) Bax, Bcl-2, and cyclin expression and apoptosis in rat substantia nigra during development. Neurosci Lett 306:198-202.

Hudson J, Granholm AC, Gerhardt GA, Henry MA, Hoffman A, Biddle P, Leela NS, Mackerlova L, Lile JD, Collins F (1995) Glial cell line-derived neurotrophic factor augments midbrain dopaminergic circuits in vivo. Brain Res Bull 36:425-432.

Jackson-Lewis V, Vila M, Djaldetti R, Guegan C, Liberatore G, Liu J, O’Malley KL, Burke RE, Przedborski S (2000) Developmental cell death in dopaminergic neurons of the substantia nigra of mice. J Comp Neurol 424:476-488

Janec E, Burke RE (1993) Naturally occurring cell death during postnatal development of the substantia nigra of the rat. Mol Cell Neurosci 4:30-35.

Kennedy RT, Jones SR, Wightman RM (1992) Dynamic observation of dopamine autoreceptor effects in rat striatal slices. J Neurochem 59:449-455.

Kordower JH, Emborg ME, Bloch J, Ma SY, Chu Y, Leventhal L, McBride J, Chen EY, Palfi S, Roitberg BZ, Brown WD, Holden JE, Pyzalski R, Taylor MD, Carvey P, Ling Z, Trono D, Hantraye P, Deglon N, Aebischer P (2000) Neurodegeneration prevented by lentiviral vector delivery of GDNF in primate models of Parkinson's disease. Science 290:767-773.

Krestel HE, Mayford M, Seeburg PH, Sprengel R (2001) A GFP-equipped bidirectional expression module well suited for monitoring tetracyclineregulated gene expression in mouse. Nucleic Acids Res 29:E39.

Ledda F, Paratcha G, Ibanez CF (2002) Target-derived GFRalphal as an attractive guidance signal for developing sensory and sympathetic axons via activation of Cdk5. Neuron 36:387-401.

Lin L-FH, Doherty DH, Lile JD, Bektesh S, Collins F (1993) GDNF: a glial cell line-derived neurotrophic factor for midbrain dopaminergic neurons. Science 260:1130-1132.

Lopez-Martin E, Caruncho HJ, Rodriguez-Pallares J, Guerra MJ, LabandeiraGarcia JL (1999) Striatal dopaminergic afferents concentrate in GDNFpositive patches during development and in developing intrastriatal striatal grafts. J Comp Neurol 406:199-206.

Macaya A, Munell F, Gubits RM, Burke RE (1994) Apoptosis in substantia nigra following developmental striatal excitotoxic injury. Proc Natl Acad Sci USA 91:8117-8121.

Mahalik TJ, Hahn WE, Clayton GH, Owens GP (1994) Programmed cell death in developing grafts of fetal substantia nigra. Exp Neurol 129:27-36.
Marti MJ, James CJ, Oo TF, Kelly WJ, Burke RE (1997) Early developmental destruction of terminals in the striatal target induces apoptosis in dopamine neurons of the substantia nigra. J Neurosci 17:2030-2039.

Mayford M, Bach ME, Huang YY, Wang L, Hawkins RD, Kandel ER (1996) Control of memory formation through regulated expression of a CaMKII transgene. Science 274:1678-1683.

Moore MW, Klein RD, Farinas I, Sauer H, Armanini M, Phillips H, Reichardt LF, Ryan AM, Carver-Moore K, Rosenthal A (1996) Renal and neuronal abnormalities in mice lacking GDNF. Nature 382:76-79.

Mosharov EV, Gong LW, Khanna B, Sulzer D, Lindau M (2003) Intracellular patch electrochemistry: regulation of cytosolic catecholamines in chromaffin cells. J Neurosci 23:5835-5845.

Mundorf ML, Joseph JD, Austin CM, Caron MG, Wightman RM (2001) Catecholamine release and uptake in the mouse prefrontal cortex. J Neurochem 79:130-142.

Nutt JG, Burchiel KJ, Comella CL, Jankovic J, Lang AE, Laws ERJ, Lozano AM, Penn RD, Simpson RKJ, Stacy M, Wooten GF (2003) Randomized, double-blind trial of glial cell line-derived neurotrophic factor (GDNF) in PD. Neurology 60:69-73.

Oo TF, Burke RE (1997) The time course of developmental cell death in phenotypically defined dopaminergic neurons of the substantia nigra. Brain Res Dev Brain Res 98:191-196.

Oo TF, Kholodilov N, Burke RE (2003) Regulation of natural cell death in dopaminergic neurons of the substantia nigra by striatal GDNF in vivo. J Neurosci 23:5141-5148.

Ouimet CC, McGuinness TL, Greengard P (1984) Immunocytochemical localization of calcium/calmodulin-dependent protein kinase II in rat brain. Proc Natl Acad Sci USA 81:5604-5608.

Paratcha G, Ledda F, Baars L, Coulpier M, Besset V, Anders J, Scott R, Ibanez CF (2001) Released GFRalphal potentiates downstream signaling, neuronal survival, and differentiation via a novel mechanism of recruitment of c-Ret to lipid rafts. Neuron 29:171-184.

Parish CL, Finkelstein DI, Drago J, Borrelli E, Horne MK (2001) The role of dopamine receptors in regulating the size of axonal arbors. J Neurosci 21:5147-5157.

Paxinos G, Franklin KBJ (2001) The mouse brain in stereotaxic coordinates New York: Academic.

Pichel JG, Shen L, Sheng HZ, Granholm A-C, Drago J, Grinberg A, Lee EJ, Huang SP, Saarma M, Hoffer BJ, Sariola H, Westphal H (1996) Defects in enteric innervation and kidney development in mice lacking GDNF. Nature 382:73-76.

Rayport S, Sulzer D, Shi WX, Sawasdikosol S, Monaco J, Batson D, Rajendran G (1992) Identified postnatal mesolimbic dopamine neurons in culture morphology and electrophysiology. J Neurosci 12:4264-4280.

Rosenblad C, Martinez-Serrano A, Bjorklund A (1998) Intrastriatal glial cell line-derived neurotrophic factor promotes sprouting of spared nigrostriatal dopaminergic afferents and induces recovery of function in a rat model of Parkinson's disease. Neuroscience 82:129-137.

Sanchez MP, Silos-Santiago I, Frisen J, He B, Lira SA, Barbacid M (1996) Renal agenesis and the absence of enteric neurons in mice lacking GDNF. Nature 382:70-73.

Sauer H, Rosenblad C, Bjorklund A (1995) Glial cell line-derived neurotrophic factor but not transforming growth factor $\beta 3$ prevents delayed degeneration of nigral dopaminergic neurons following striatal 6-hydroxydopamine lesion. Proc Natl Acad Sci USA 92:8935-8939.

Schaar DG, Sieber BA, Dreyfus CF, Black IB (1993) Regional and cell specific expression of GDNF in rat brain. Exp Neurol 124:368-371.

Schmitz Y, Lee CJ, Schmauss C, Gonon F, Sulzer D (2001) Amphetamine distorts stimulation-dependent dopamine overflow: effects on D2 autoreceptors, transporters, and synaptic vesicle stores. J Neurosci 21:5916-5924.

Scholz WK, Baitinger C, Schulman H, Kelly PT (1988) Developmental changes in $\mathrm{Ca}^{2+} /$ calmodulin-dependent protein kinase II in cultures of hippocampal pyramidal neurons and astrocytes. J Neurosci 8:1039-1051.

Schultz W (1982) Depletion of dopamine in the striatum as an experimental model of Parkinsonism: direct effects and adaptive mechanisms. Prog Neurobiol 18:121-166.

Stromberg I, Bjorklund L, Johansson M, Tomac A, Collins F, Olson L, Hoffer B, Humpel C (1993) Glial cell line derived neurotrophic factor is expressed in the developing but not adult striatum and stimulates developing dopamine neurons in vivo. Exp Neurol 124:401-412.

Tomac A, Lindqvist E, Lin L-FH, Ogren SO, Young D, Hoffer BJ, Olson L 
(1995a) Protection and repair of the nigrostriatal dopaminergic system by GDNF in vivo. Nature 373:335-339.

Tomac A, Widenfalk J, Lin LH, Kohno T, Ebendal T, Hoffer BJ, Olson L (1995b) Retrograde axonal transport of glial cell line-derived neurotrophic factor in the adult nigrostriatal system suggests a trophic role in the adult. Proc Natl Acad Sci USA 92:8274-8278.

Weiner N (1985) Norepinephrine, epinephrine, and the sympathomimetic amines. In: The pharmacologic basis of therapeutics (Gilman AG, Goodman LS, Rall TW, Murad F, eds), pp 145-180. New York: Macmillan.

Widenfalk J, Nosrat C, Tomac A, Westphal H, Hoffer B, Olson L (1997) Neurturin and glial cell line-derived neurotrophic factor receptor-beta (GDNFR-beta), novel proteins related to GDNF and GDNFR-alpha with specific cellular patterns of expression suggesting roles in the developing and adult nervous system and in peripheral organs. J Neurosci 17:8506-8519.

Wightman RM, Zimmerman JB (1990) Control of dopamine extracellular concentration in rat striatum by impulse flow and uptake. Brain Res Rev 15:135-144.

Yamamoto A, Lucas JJ, Hen R (2000) Reversal of neuropathology and motor dysfunction in a conditional model of Huntington's disease. Cell 101:57-66.

Yu T, Scully S, Yu Y, Fox GM, Jing S, Zhou R (1998) Expression of GDNF family receptor components during development: implications in the mechanisms of interaction. J Neurosci 18:4684-4696. 